\title{
PENGARUH KREDIBILITAS, REPUTASI, DAN KEMAMPUAN PERSUASIF FOOD BLOGGERS TERHADAP INTENSI KONSUMEN DALAM MEMILIH SEBUAH RESTORAN
}

\author{
Melly Audina \\ Program Studi Magister Manajemen Universitas Tarumanagara \\ melly.audina@gmail.com
}

\begin{abstract}
The impact of globalization has affected many aspects in the development of human life. Over time, the internet has become one of the human needs to survive in this era of globalization. The use of the internet in the world of marketing is not a taboo thing for the people of Indonesia, especially Jakarta. This study aims to determine the effect of reputation, credibility, and persuasive ability of each or simultaneously on the intensity of consumers in choosing a restaurant. The research methodology used is in the form of a quantitative test carried out by distributing questionnaires to 148 respondents and analyzed by SPSS Statistics 22 application. The results of the analysis show that all variables are declared valid and reliable. The credibility variable is considered to have a significant influence on the intention of choosing a restaurant. Reputable variables do not have a significant effect on the selection of a restaurant because the established and strong restaurant names are not affected by the reputation of endorsers. The variable persuasive ability has a significant influence on the selection of a restaurant. Variables of credibility, reputation, and persuasive abilities of food bloggers have a close relationship with consumer purchasing decisions.
\end{abstract}

Abstrak: Dampak adanya globalisasi telah mempengaruhi banyak aspek dalam perkembangan kehidupan manusia. Seiring berjalannya waktu, internet telah menjadi salah satu kebutuhan manusia untuk bertahan hidup di era globalisasi ini. Pemanfaatan internet dalam dunia pemasaran tidak menjadi hal yang tabu bagi masyarakat Indonesia, khususnya Jakarta. Penelitian ini bertujuan untuk mengetahui pengaruh reputasi, kredibilitas, dan kemampuan persuasif masing-masing maupun secara bersamaan terhadap intensi konsumen dalam memilih sebuah restoran. Metodologi penelitian yang digunakan berupa uji kuantitatif yang dilakukan dengan penyebaran kuisioner terhadap 148 responden dan dianalisis dengan aplikasi SPSS Statistics 22. Hasil dari analisis menunjukkan bahwa seluruh variabel dinyatakan valid dan reliabel. Variabel kredibilitas dinilai memberikan pengaruh signifikan terhadap intensi pemilihan sebuah restoran. Variabel reputasi tidak memberikan pengaruh signifikan terhadap pemilihan sebuah restoran karena nama restoran yang sudah mapan dan kuat tidak terpengaruh oleh reputasi endorser. Variabel kemampuan persuasif memberikan pengaruh signifikan terhadap pemilihan sebuah restoran. Variabel kredibilitas, reputasi, dan kemampuan persuasif dari food blogger memiliki hubungan yang erat terhadap keputusan pembelian konsumen.

Keywords: credibility, reputation, persuasive abilities, food bloggers, restaurant, purchasing decisions.

\section{PENDAHULUAN \\ Latar Belakang}

Semua makhluk hidup membutuhkan makanan untuk kelangsungan hidupnya. Keperluan pangan sudah menjadi kebutuhan primer bagi seluruh umat manusia. Berbagai restoran dan tempat makan beroperasi untuk memenuhi kebutuhan manusia. Semakin banyak pilihan restoran dan jenis makanan yang kaya menjadikan persaingan antar restoran dalam menarik perhatian konsumen tak terelakan. Kemampuan teknologi yang semakin berkembang 
menyebabkan mudahnya proses penyampaian emosi, opini, dan ide di berbagai kejadian yang kita alami sepanjang hari. Menurut Suryani (2013), perkembangan teknologi internet telah mempengaruhi berbagai aspek kehidupan, salah satunya perilaku konsumen. Adanya internet merubah cara masyarakat memperoleh informasi, kebutuhan mengambil keputusan tanpa terbatas ruang dan waktu, dan kebutuhan untuk mengaktualisasikan diri di dunia maya.

Pemanfaatan food blogger diperkirakan akan terus meningkat karena mampu memperkenalkan suatu merek baru kepada calon konsumen. Perkenalan merek menjadi penting untuk meningkatkan kesadaran merek, meski belum tentu berpengaruh sejalan terhadap peningkatan penjualan. Menurut Kotler dan Keller (2013) blogger adalah salah satu platform media sosial selain forum online dan jejaring sosial (Facebook, Twitter, Youtube). Blog yang diupdate secara teratur akan menjadi saluran word-of-mouth. Ulasan yang diberikan oleh blogger dapat menjadi rekomendasi konsumen terhadap brand attitudes, purchasing attitudes, dan advertising attitudes. Apabila ulasan yang diberikan semakin baik, maka akan meningkatkan minat pembelian calon konsumen. Berbagai restoran dengan gelar top brands sudah banyak menyadari hal ini dan berfokus untuk menggencarkan pemasaran di media sosial (Lusiyanti, 2017).

Penulis tertarik mengetahui apakah food blogger mempengaruhi intensi pembelian masyarakat di sebuah restoran. Batasan yang saya tambahkan agar penelitian ini tidak terlalu luas, meliputi pengaruh kredibilitas (dalam hal keterpercayaan, keahlian, daya tarik), reputasi, dan kemampuan persuasif food blogger terhadap intensi konsumen memilih restoran.

\section{Tujuan Penelitian}

Penelitian ini berupa perlakuan uji hipotesis yang bertujuan untuk mengetahui pengaruh masing-masing maupun secara bersamaan antar variabel kredibilitas, reputasi, dan kemampuan persuasif food blogger terhadap pemilihan restoran.

\section{LANDASAN TEORI \\ Intensi Pembelian}

Intensi pembelian merupakan motivasi atau dorongan yang menunjukkan adanya usaha atau kesiapan seseorang untuk menampilkan perilaku membeli. Semakin besar intensi pembelian, maka akan semakin besar peluang pembelian (Rahmah, 2011). Menurut Ajzen dan Fishbein (1980), intensi pembelian dapat diartikan sebagai kesiapan atau kemauan individu untuk membeli. Hal ini menjelaskan bahwa intensi merupakan bagian dari diri manusia yang melibatkan hubungan antara dirinya dan tindakan yang dipengaruhi kemungkinan dimensi subjektif (Wu, et al., 2011).

Definisi intensi menjadi topik penting karena hubungannya dengan prediksi tingkah laku. Tingkah laku yang dibahas dalam psikologi sosial berkaitan dengan tindakan di bawah kontrol atau kesadaran. Individu akan melakukan suatu tingkah laku hanya jika ia benarbenar ingin melakukannya dan akhirnya membentuk sebuah intensi. Berdasarkan pernyataan para ahli tersebut, disimpulkan bahwa intensi adalah kemungkinan seseorang menampilkan perilaku tertentu dengan faktor motivasional yang mempengaruhi bagaimana usaha yang dilakukan untuk menampilkan perlaku tersebut (Rahmah, 2011).

\section{Kredibilitas}

Kredibilitas sumber adalah suatu indikator yang menunjukkan apakah seorang individu merupakan sumber informasi yang memihak, benar atau faktual, dan terpercaya (Hass, 1981). Teori kredibilitas menunjukkan bahwa orang akan mempunyai kecenderungan untuk lebih terbujuk saat suatu sumber menunjukkan dirinya sebagai sumber yang kredibel (Ohanian, 1990). Nilai positif yang didapatkan oleh suatu sumber akan menambah nilai dan berefek terhadap peningkatan penerimaan penerima sumber atau konsumen (Long, et al., 2014). Apabila pesan yang diterima oleh konsumen dirasa menyimpang dan disajikan bukan 
dengan alasan untuk menyampaikan pengalaman sumber kepada konsumen, maka akan menurunkan kredibilitas sumber dan menentang intensi persuasif pesan sumber (Lee dan Koo, 2012).

Informasi online dari sumber asli yang diakui banyak orang pastinya akan dipilih oleh banyak individu. Setiap individu berharap pada ulasan yang positif dan kredibel. Apabila suatu sumber dinilai kredibel, maka akan menimbulkan rasa percaya pada individu tersebut. Kredibilitas sumber dapat dihasilkan dari ulasan online, desain yang diciptakan perusahaan, tanda atau simbol yang meyakinan (Soenarno, et al., 2015). Oleh karena itu, menurut Ohanian (1990), Indikator variabel dari kredibilitas adalah keahlian, keterpercayaan, dan daya tarik.

\section{Reputasi}

Reputasi adalah nilai yang diberikan oleh konsumen atas pengalaman atau pelayanan yang diterimanya. Reputasi berbanding lurus dengan kredibilitas sumber, apabila suatu sumber mendapatkan reputasi yang baik, maka akan meningkatkan kredibilitasnya. Sumber yang berkredibilitas akan membuat konsumen lebih percaya diri untuk mendapatkan apa yang dijanjikan kepada mereka. Reputasi menjadi jaminan bagi konsumen untuk mendapatkan produk atau jasa yang sesuai dengan ekspektasi konsumen (Lusiyanti, 2017).

Reputasi dimanfaatkan sebagai nilai kepercayaan atau niat perilaku. Berdasarkan beberapa studi empiris, kepercayaan dan niat perilaku dipengaruhi oleh reputasi (Casalo, et al., 2008; Keh dan Xie, 2009; Koufaris dan Hamption-Sosa, 2004). Menurut Hsu, et al. (2013), blogger yang membahas suatu konten tertentu dan memiliki reputasi berbeda akan mempengaruhi persepsi pembaca secara berbeda pula. Studi terdahulu menunjukkan bahwa konsumen akan memiliki kencenderungan menimang informasi dari sumber yang reputasinya baik (Lutz, 1985; Mackenzie dan Lutz, 1989).

\section{Kemampuan Persuasif}

Kemampuan persuasif adalah suatu tindakan komunikasi yang digunakan untuk meyakinkan orang lain. Persuasi individu dilakukan untuk mempengaruhi kepercayaan dan ekspektasi seorang pribadi. Usaha memersuasifkan adalah suatu strategi yang digunakan untuk menyampaikan pesan agar pesan tersebut dapat tersampaikan atau dimengerti orang lain (Janasz, et al., 2014).

Seorang pemimpin opini harus memiliki kemampuan persuasif (Lusiyanti, 2017). Adanya kemampuan persuasif dari sebuah sumber, maka akan sangat mudah untuk meyakinkan orang lain terhadap suatu ide, konsep, merek suatu produk baru (Chaovalit, 2014). Kemampuan persuasif merupakan upaya untuk mengubah, memperkuat, menggoyahkan keyakinan atau pendapat seseorang. Perubahan keyakinan atau pendapat akan mempengaruhi perilaku konsumen dalam memilih suatu tindakan. Pemahaman mengenai kemampuan persuasif secara psikologi yaitu memahami mengapa seorang dapat berpikir atau bertindak dengan cara tertentu (Hovland, 1953).

\section{Model Penelitian}

Pada model penelitian ini garis $\mathrm{H} 1, \mathrm{H} 2$, dan $\mathrm{H} 3$ menunjukkan pengaruh langsung terhadap variabel pemilihan restoran. 


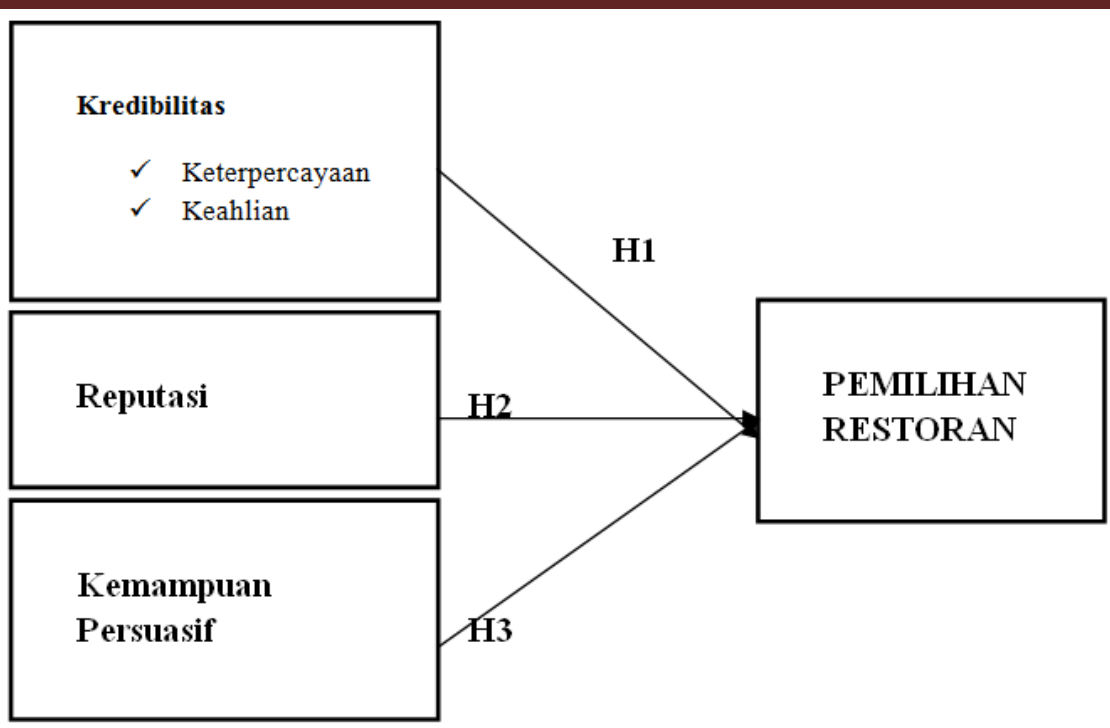

\section{Hipotesis Penelitian}

Gambar 2.1 Kerangka Pemikiran

Kerangka pemikiran yang ada selanjutnya menghantarkan kepada hipotesis dari penelitian ini, yang diantaranya adalah sebagai berikut:

$\mathrm{H} 1=$ Kredibilitas berpengaruh terhadap pemilihan sebuah restoran.

$\mathrm{H} 2$ = Reputasi berpengaruh terhadap pemilihan sebuah restoran.

H3 = Kemampuan persuasif berpengaruh terhadap pemilihan sebuah restoran.

\section{METODE PENELITIAN}

Penelitian ini menggunakan kuesioner sebagai sumber data primer yang akan menguji pengaruh food bloggers berdasarkan kredibilitas, reputasi, dan kemampuan persuasifnya. Teknik sampling yang digunakan dalam penelitian ini adalah simple random sampling atau non-probability sampling. Teknik ini dianggap sebagai populasi yang homogen sehingga setiap unsur dalam populasi tidak mempunyai peluang yang sama untuk dipilih sebagai sampel. Teknik selanjutnya yang digunakan dalam pemilihan sampel adalah convenience judgement sampling, yaitu responden bersedia dan dapat membantu menjawab pertanyaan yang diajukan untuk keperluan penelitian ini.

Target responden dari penelitian ini adalah pria maupun wanita yang berusia $15-40$ tahun yang mengikuti atau membaca ulasan food blogger dan berkediaman di Jakarta Utara. Kuisioner akan disebarkan secara langsung ke beberapa titik daerah di Jakarta Utara. Beberapa bagian kota Jakarta Utara, mulai dari Pluit, Kelapa Gading, dan Sunter akan diambil beberapa responden untuk dijadikan sampel representatif.

Pertanyaan yang akan diajukan sejumlah 30 pernyataan yang terdiri dari 5 aspek utama yang ingin diuji dari pengaruh food bloggers. Aspek utama yang akan diuji berupa:

- keterepercayaan food bloggers

- level keahlian food blogger

- daya tarik food bloggers

- reputasifood bloggers

- kemampuan persuasif food bloggers

Pilihan jawaban dari pertanyaan-pertanyaan tersebut berupa skala yang berjumlah 5 poin skala Likert dan terdiri atas:

- $\quad$ sangat tidak setuju (STS) bernilai 1

- tidak setuju (TS) bernilai 2

- biasa saja (BS) bernilai 3

- $\quad$ setuju (S) bernilai 4 
- $\quad$ sangat setuju (SS) bernilai 5

Data yang diperoleh akan diuji validitas, reliabilitas, normalitas, multikolinearitas, heteroskedastisitas, uji linear berganda, uji F, uji koefisien determinasi, uji t, dan uji analisis linear berganda.

\section{HASIL DAN PEMBAHASAN}

\section{Uji Analisis Linear Berganda}

Tabel 4.1 Hasil Uji Linear Berganda

\begin{tabular}{|l|r|r|r|r|r|}
\hline \multirow{2}{*}{ Dimensi } & \multicolumn{2}{|c|}{ Unstandardized Coefficients } & $\begin{array}{c}\text { Standardized } \\
\text { Coefficients }\end{array}$ & \multirow{2}{*}{ T } & \multirow{2}{*}{ Sig. } \\
\cline { 2 - 4 } & $\mathbf{B}$ & $\begin{array}{c}\text { Std. } \\
\text { Error }\end{array}$ & \multicolumn{1}{|c|}{ Beta } & & \\
\hline (Constant) & 2,693 & 0,269 & & 10,02 & 0,000 \\
\hline Kredibilitas & 0,324 & 0,120 & 0,352 & 2,704 & 0,008 \\
\hline Reputasi & $-0,192$ & 0,082 & $-0,232$ & 2,354 & 0,020 \\
\hline $\begin{array}{l}\text { Kemampuan } \\
\text { Persuasif }\end{array}$ & 0,116 & 0,081 & 0,163 & 1,440 & 0,001 \\
\hline
\end{tabular}

dengan menggunakan model dasar persamaan regresi linier berganda dihasilkan persamaan sebagai berikut:

$$
\mathrm{Y}=\mathrm{b}_{0}+\mathrm{b}_{1} \mathrm{X}_{1}+\mathrm{b}_{2} \mathrm{X}_{2}+\mathrm{b}_{3} \mathrm{X}_{3}+\mathrm{e} \ldots(1)
$$

dan dengan menyesuaikan jumlah variabel dimensi (kredibilitas $(\mathrm{X} 1)$, reputasi $\left(\mathrm{X}_{2}\right)$, dan kemampuan persuasif $\left(\mathrm{X}_{3}\right)$ serta memasukkan hasil pada tabel di atas ke persamaan (1), maka di dapatkan persamaan (2):

$$
\mathrm{Y}=2,693+0,324 \mathrm{X}_{1}-0,192 \mathrm{X}_{2}+0,116 \mathrm{X}_{3}+0,269
$$

dikarenakan pengukuran variabel dimensi pada penelitian ini menggunakan skala Likert yang mana nilai terendah adalah 1 , sehingga $X_{1}, X_{2}$, dan $X_{3}$ tidak mungkin bernilai 0. Sehingga persamaan (2) tersebut harus ditulis dalam bentuk standardized coefficients (Supranto, 2001 dalam Runiasari, 2008) sehingga persamaan regresi linier berganda dalam penelitian ini adalah:

$$
\mathrm{Y}=0,352 \mathrm{X}_{1}-0,232 \mathrm{X}_{2}+0,163 \mathrm{X}_{3}
$$

Persamaan regresi tersebut dapat dijelaskan sebagai berikut:

- Koefisien variabel dimensi kredibilitas $\left(\mathrm{X}_{1}\right)$ diperoleh sebesar 0,352 dengan tanda positif. Hal ini menunjukkan apabila semakin kredibel seorang food blogger, maka semakin berpengaruh signifikan terhadap pemilihan sebuah restoran (Y) sebesar $35,2 \%$.

- Koefisien variabel dimensi reputasi $\left(\mathrm{X}_{2}\right)$ diperoleh sebesar 0,232 dengan tanda negatif. Hal ini menunjukkan apabila semakin tinggi reputasi seorang food blogger, maka tidak akan member pengaruh signifikan terhadap pemilihan sebuah restoran (Y) sebesar $-23,2 \%$.

- Koefisien variabel dimensi kemampuan persuasif $\left(X_{3}\right)$ diperoleh sebesar 0,163 dengan tanda positif. Hal ini menunjukkan apabila semakin tinggi kualitas kemampuan persuasif seorang food blogger, maka semakin berpengaruh signifikan terhadap pemilihan sebuah restoran (Y) sebesar 16,3\%.

Dari hasil koefisien regresi berganda yang telah dijelaskan pada uraian di atas, selanjutnya akan dilakukan pengujian hipotesis yang dilakukan secara parsial maupun simultan. 


\section{Uji Hipotesis}

Uji F

Uji statistik F menunjukkan apakah semua variabel independen yang dimasukkan ke dalam model mempunyai pengaruh secara bersamaan terhadap variabel dependen. Hasil perhitungan uji statistik $\mathrm{F}$ adalah sebagai berikut:

Tabel 4.2 Uji F

\begin{tabular}{|l|c|c|c|c|c|}
\hline \multicolumn{1}{|c|}{ Model } & Sum of Squares & Df & Mean Square & F & Sig. \\
\hline Regression & 5,348 & 3 & 1,783 & 8,634 & 0,000 \\
\hline Residual & 29,730 & 144 & 0,206 & & \\
\hline
\end{tabular}

Pada Tabel 4.5 menunjukkan hasil uji ANOVA $\left(\mathrm{F}_{\text {hitung }}\right)$ sebesar 8,634 dengan tingkat signifikan sebesar 0,000. Nilai sig $0,000<0,05$ menunjukkan nilai variabel kredibilitas, reputasi, dan kemampuan persuasif mempengaruhi secara positif variabel pemilihan sebuah restoran.

\section{Uji t}

Uji statistik t bertujuan untuk mengetahui sejauh mana pengaruh dimensi variabel independen secara individual dalam menjelaskan variabel dependen (Ghozali, 2006).

Tabel 4.3 Uji t

\begin{tabular}{|l|c|c|c|}
\hline \multirow{2}{*}{ Dimensi } & Standardized Coefficients & \multirow{2}{*}{ S } & Sig. \\
\cline { 2 - 2 } & Beta & & \\
\hline Kredibilitas & 0,352 & 2,704 & 0,008 \\
\hline Reputasi & $-0,232$ & $-2,354$ & 0,020 \\
\hline Kemampuan Persuasif & 0,163 & 1,440 & 0,001 \\
\hline
\end{tabular}

Hasil analisis regresi menunjukkan bahwa kredibilitas dan kemampuan persuasif food bloggers memberikan pengaruh positif dan signifikan terhadap pemilihan sebuah restoran, namun variabel reputasi tidak memberikan pengaruh signifikan terhadap pemilihan sebuah restoran, sehingga dapat disimpulkan sebagai berikut:

H1 = Kredibilitas berpengaruh terhadap pemilihan sebuah restoran, diterima.

$\mathrm{H} 2$ = Reputasi berpengaruh terhadap pemilihan sebuah restoran, ditolak.

H3 = Kemampuan persuasif berpengaruh terhadap pemilihan sebuah restoran, diterima.

Berdasarkan hasil uji t (standardized coefficient beta) pada tabel 4.3 tersebut, dapat diketahui bahwa variabel dimensi kredibilitas $(0,352)$ menjadi variabel yang paling dominan pengaruhnya terhadap tingkat kepuasan pelanggan. Selanjutnya, berturut-turut yaitu variabel dimensi kemampuan persuasif $(0,163)$ dan variabel dimensi reputasi $(-0,232)$.

\section{KESIMPULAN}

\section{Kesimpulan}

Berdasarkan hasil dari analisis dan pengujian data yang telah dilakukan maka kesimpulan yang didapatkan adalah sebagai berikut:

- Adanya pengaruh signifikan positif yang diberikan dimensi kredibilitas terhadap pemilihan sebuah restoran.

- Adanya pengaruh negatif yang diberikan dimensi reputasi terhadap pemilihan sebuah restoran.

- Adanya pengaruh signifikan positif yang diberikan dimensi kemampuan persuasif terhadap pemilihan sebuah restoran.

- Dimensi kredibilitas memiliki pengaruh yang paling dominan terhadap pemilihan sebuah restoran. 


\section{DAFTAR PUSTAKA}

Casalo, L., Flavian, C., dan Guinaliu, M. 2008. The role of perceived usability, reputuation, satisfaction and consumer familiarity on the websiteloyalty formation process. Computers in Human Behavior, 24 (2), 325-345.

Chaovalit, P. 2014. Factors Influencing Cosmetics Purchase Intention in Thailand: A Study on the Relationship of Credibility and Reputation with in Persuasive Capabilities of Beauty Bloggers. Assumption University of Thailand. Vol 7, No. 1.

Fishbein, M. dan Ajzen, I. 1975. Belief, sttitude, intention and behavior: an introduction to theory and research. Reading, Mass: Adisson-Wesley.

Ghozali, I. (2005). Aplikasi Analisis Multivariate Dengan Program SPSS. Semarang: Universitas Diponegoro.

Hass, R. G. 1981. Effect of source characteristics on cognitive responses and persuasion. In R. E.

Hovland, C. I., Janis, I. L., Kelly, H. H. 1953. Communication and persuasion: psychological studies in opinion charge. American Sosiological Review, 19(3), 355-357.

Hsu, C. L., Lin, J. C., dan Chiang, H. S. 2013. The effects of blogger recommendations on customers' online shopping intentions. Internet Research, 23(1), 69-88.

Janasz, S., Dowd, K., dan Schneider, B. 2014. Interpersonal skills in organization $\left(5^{\text {th }}\right.$ edition).

Kotler, P. and Gerald Z. 1971. Social marketing: an approach to planned social change. Journal of Marketing. Diakses pada tanggal 20 Oktober 2017 dari http://www.sfu.ca/cmns /faculty/ laba_m/425/07-fall/documents/Kotler-Zaltman. Pdf

Lee, K. T. dan Koo, D. M. 2012. Effect of attribute and valence of e-WOM on message adoption: moderating roles of subjective knowledge and regulatory focus. Computers in Human Behavior, 28, 1974-1984.

Lusiyanti. 2017. Pengaruh kredibilitas, reputasi, dan kemampuan persuasive beauty bloggers terhadap intensi pembelian produk kosmetik di Indonesia. Skripsi, Universitas Tarumanagara, Jakarta.

Lutz, R. J. 1985. Afective and cognitive antecedents of attitude toward the ad: a conceptual framework. Hillsdale, NJ: Erlbaun Group.

Ohanian, R. 1990. Construction and validation of a scale to measure celebrity endorsers' perceived expertise, trustworthiness, and attractiveness. Journal of Advertising, 19 (3), 39-52.

Rahmah. 2011. Pengaruh sikap, norma subjektif, dan perceived behavioral control terhadap intensi membeli buku referensi kuliah ilegal pada mahasiswa uin syarif hidayatullah jakarta. Skripsi, Universitas Negeri Syarif Hidayatullah, Jakarta.

Soenarno, A. R. P., Suharyono, dan Mawardi, M. K. 2015. Analisis pengaruh kualitas informasi dan kredibilitas sumber terhadap kegunaan informasi dan dampaknya pada adopsi informasi (studi pada masyarakat pengikut akun twitter resmi iKaskus). Jurnal Administrasi Bisnis (JAB) Vol. 25 No. 1.

Suryani, T. 2013. Perilaku konsumen di era internet: implikasinya pada strategi pemasaran. Yogyakarta: Graha Ilmu. 
